\title{
Desajustes entre las percepciones familiares y docentes sobre la implicación parental. Un estudio etnográfico en la educación secundaria obligatoria $^{1}$
}

\author{
Mismatches between Parents' and Teachers' Perceptions \\ of Parental Involvement. An Ethnographic Study \\ in Compulsory Secondary Education
}

Carmona, Carlos Alonso (2021). Desajustes entre las percepciones familiares y docentes sobre la implicación parental. Un estudio etnográfico en la educación secundaria obligatoria. Recerca. Revista de Pensament i Análisi, 26(2), pp. 1-22.

doi: http://dx.doi.org/10.6035/recerca.5750

\section{Resumen}

El artículo analiza cómo el profesorado percibe la implicación escolar de los progenitores del alumnado y compara dichas percepciones con la implicación declarada por los propios progenitores. Se realizaron entrevistas en profundidad a madres y padres de alumnado de secundaria en dos momentos de la carrera escolar filial y se realizó observación etnográfica en los institutos a los que acuden los hijos e hijas. Los resultados muestran importantes distancias entre las percepciones del profesorado y los comportamientos expuestos por las familias. Los docentes sobreestiman el apoyo parental que recibe el alumnado de alto rendimiento, e infraestiman el apoyo que recibe el alumnado de bajo rendimiento. Las estrategias y actitudes de los hijos e hijas juegan un papel clave para explicar estas percepciones.

Palabras clave: percepciones docentes, educación secundaria, implicación familiar, relación familiaescuela.

Este artículo se enmarca en el desarrollo de una beca FPU (ref. 14/00678) financiada por el Ministerio de

Educación, Cultura y Deporte. 


\section{Abstract}

The article analyses how teachers perceive parental school involvement and compares said perceptions with the involvement declared by parents. In-depth interviews were conducted to parents of middle-school students during two moments of their children's educational career and ethnographic observation was performed in their children's schools. Results show that, in most cases, teachers' perceptions do not match what is exposed by the families. Faculty overestimate the family support received by high achieving students, and underestimate the support received by low achievers. Children's strategies and attitudes play a key role in order to explain these perceptions.

Key Words: Teachers' perceptions, secondary education, family involvement, family-school relationships.

\section{INTRODUCCIÓN}

Desde la década de los ochenta, la retórica de la implicación parental en la escuela ha ganado mucha fuerza en la agenda educativa de los países desarrollados (Cerletti y Santillán, 2018). El concepto de implicación designa una serie de comportamientos parentales que influirían en el rendimiento académico de los hijos e hijas: vigilancia y apoyo con las tareas, transmisión de expectativas, contacto con el profesorado, sanciones ligadas a resultados, etc. El planteamiento de que esta implicación promueve el éxito escolar es muy popular entre el profesorado, aunque la evidencia empírica al respecto es controvertida (Alonso Carmona, 2014; Robinson y Harris, 2014).

La implicación parental se ha analizado tanto desde el punto de vista de las familias como del profesorado. La puesta en común de ambas líneas de investigación plantea recurrentemente una paradoja. La inmensa mayoría de los progenitores declara dedicar grandes esfuerzos a impulsar la carrera escolar filial. Los docentes, sin embargo, perciben que las familias no se comprometen lo suficiente con los estudios de sus hijos.

El objetivo de esta investigación es examinar las causas de este desajuste, analizando las prácticas parentales, las percepciones docentes de las mismas y la interacción efectiva entre progenitores y profesorado. Este artículo parte de una investigación cualitativa longitudinal, que combina entrevistas en profundidad a progenitores de alumnado de ESO con observación etnográfica en los institutos a los que acuden sus hijos e hijas. 


\section{LAS FAMILIAS DEL ALUMNADO EN LOS DISCURSOS DOCENTES}

Multitud de investigaciones en España se han interesado por los juicios docentes sobre las familias del alumnado (Cabrera, Cabrera, Pérez y Zamora, 2011; Garreta Bochaca, 2017; Gomáriz Vicente, Hernández-Prados, GarcíaSanz y Parra-Martínez, 2016; López Larrosa, Richards, Morao Rodríguez y Gómez Soriano, 2019; Morales Romo, 2006; Pérez Sánchez y Noda Rodríguez, 2012). Estos estudios encuentran que el profesorado, por una parte, señala el apoyo familiar como un importante factor explicativo del éxito escolar y, por otra, considera que dicho apoyo es, generalmente, escaso. Esta última percepción resulta chocante, pues la literatura muestra que los progenitores -en todos los estratos sociales- invierten cada vez más recursos y energías en promocionar la escolaridad filial (Pérez Díaz, Rodríguez y Fernández, zoog; Martín Gimeno y Bruquetas Callejo, 2014).

Las investigaciones que se han acercado al discurso docente mediante técnicas cualitativas (Castejón, 2017; Rujas, 2016; Tarabini, 2015; Río Ruiz, 2010) muestran un escenario similar, aunque con matices. Más que a una implicación con valor instructivo, los docentes refieren al interés o la preocupación de la familia por la escuela: los comportamientos de apoyo se valoran como muestra de ese interés, como su manifestación visible. Por otro lado, bajo los conceptos de implicación o interés el profesorado suele juzgar todo un modo de socialización familiar (vínculos con los hijos, disciplina del hogar, consumo cultural, etc.), más allá del seguimiento de los estudios filiales.

El profesorado percibe menos apoyo y preocupación por la escuela en las familias de estratos sociales inferiores (Lareau, 200o). Aquí el discurso docente oscila entre varias atribuciones causales: por sus carencias materiales básicas, estas familias no verían la educación como una prioridad, carecerían de aspiraciones o desearían que sus hijos e hijas accediesen tempranamente al mercado laboral (Castejón, 2017; Río Ruíz, 2010).

Las diferencias de capital cultural (Bourdieu, 1987) son especialmente relevantes para explicar la desigual percepción que el cuerpo docente tiene sobre las familias de distintas clases sociales (Weininger y Lareau, 2003). Estas percepciones condicionan su trato con el alumnado (Castejón, 2017), por lo que la interacción familia-profesorado podría constituir un mecanismo de reproducción de las desigualdades de clase a través del sistema escolar (Lareau, 2000). 


\section{LAS PERCEPCIONES DOCENTES Y SU DISTANCIA RESPECTO A LOS COMPORTAMIENTOS FAMILIARES}

Aunque las familias están muy presentes en las atribuciones docentes del éxito escolar, el profesorado tiene poca información sobre lo que sucede en los hogares de su alumnado. Los docentes infieren los comportamientos familiares a partir de ciertas evidencias a las que tienen acceso (Rujas, 2016). En ese sentido, la asistencia regular de la familia al centro suele ser valorada como el principal indicador de su interés por la escuela (Castejón, 2017; Madrid, Saracostti, Reininger y Hernández, 2019; Lawson, 2003).

Sin embargo, muchos juicios docentes sobre las familias no se construyen en interacción con los progenitores, sino con sus hijos e hijas (Perrenoud, 1987). A ojos del profesorado, el comportamiento o el rendimiento de un alumno puede ser revelador del grado de implicación de sus progenitores: «se juzga entonces una socialización familiar que no es directamente visible para los docentes, a partir de las marcas de la misma que creen ver en sus alumnos» (Rujas, 2016: 3).

Varias investigaciones señalan que los juicios docentes sobre las familias no siempre coinciden con lo expuesto por las propias familias (Iruka, Winn, Kingsley y Orthodoxou, 2011; Minke et al., 2014), sobre todo cuando el alumnado pertenece a grupos sociales subalternos (Wong y Hughes, 2006; Lareau, 2000). Muchas familias de estratos inferiores evitan relacionarse con los docentes y son, por tanto, etiquetadas como «poco implicadas» en los centros. Sin embargo, esas mismas familias tratan de prestar apoyo escolar en el hogar (Allen y White-Smith, 2018; Martín Criado, Carvajal Soria y Río Ruíz, 2014). El estatus social familiar correlaciona más con la implicación percibida por el profesorado que con la implicación declarada por los progenitores (Bakker, Denessen y Brus-Laeven, 2007).

En síntesis, los profesores parecen deducir el interés y el apoyo escolar de la familia en función de su presencia regular en la escuela, del comportamiento filial y del estatus social parental. Pero sus estimaciones no siempre coinciden con las versiones que dan las propias familias. En este artículo se utilizan métodos cualitativos para tratar de averiguar a qué se debe esta discordancia, analizando por qué la implicación escolar de muchas familias no es adecuadamente captada en los centros. 


\section{MÉTODO}

Este artículo parte de una investigación longitudinal que emplea metodología cualitativa. Se realizaron un total de 30 entrevistas a progenitores de distinta extracción social en dos tandas diferentes. El primer contacto tuvo lugar durante el primer trimestre del curso escolar 2016-2017, momento en que los entrevistados tenían un hijo que acababa de acceder a 1.ํㅡㄹ de ESO. Las entrevistas abordaron la relación con la escolaridad filial, las medidas tomadas en el hogar para promocionarla y la vinculación familiar con los centros y sus profesionales. Durante los dos primeros trimestres del curso escolar 2016-2017, se realizó observación etnográfica en los tres institutos a los que acudían los hijos e hijas de los progenitores entrevistados. Se comenzó con observaciones en las reuniones iniciales con las familias del alumnado y se asistió semanalmente a las reuniones de coordinación de tutores. Además, se observaron las reuniones individuales de tutoría entre algunos de los progenitores entrevistados y los profesores-tutores de sus hijos e hijas (estas últimas pudieron ser grabadas en audio y analizadas en profundidad). A lo largo del trabajo etnográfico en los centros, se procuró recoger la máxima información posible sobre las familias entrevistadas, durante conversaciones con los tutores antes y después de las distintas reuniones (especialmente, antes y después de las reuniones de tutoría). Los progenitores volvieron a ser entrevistados durante el tercer trimestre del curso escolar 2017-2018.

Los tres institutos comparten la titularidad pública, pero difieren en la composición social de su alumnado. El IES Jorge Manrique es un centro de prestigio local, que recluta a sus estudiantes de entre las clases medias y medias-altas. El IES Alcázar escolariza a un alumnado relativamente heterogéneo. La mayoría de su público proviene de fracciones estables de las clases populares, con minorías del alumnado perteneciente tanto a la clase media como a familias muy precarias. El IES García Lorca se encuentra en una localidad de mediano tamaño tradicionalmente agrícola, a treinta kilómetros de la capital. Está situado en el barrio más humilde del municipio y la práctica totalidad de su alumnado pertenece a las clases populares. ${ }^{2}$

Los progenitores fueron inicialmente contactados a través de los propios centros, solicitándose su participación voluntaria durante la reunión inicial

2 Los nombres de los tres centros han sido alterados para garantizar el anonimato. 
con las familias del alumnado. La investigación se presentó como un estudio sobre los cambios de comportamiento con la llegada de la adolescencia y sus consecuencias en la vida escolar y doméstica. Las entrevistas fueron realizadas en los hogares, a excepción de dos de ellas, realizadas en los lugares de trabajo. En consonancia con los estándares éticos de la investigación sociológica, las personas participantes fueron invitadas a firmar un consentimiento informado. Este documento, redactado en un lenguaje claro y sencillo, exponía los motivos de la investigación, clarificaba el carácter voluntario de la participación y aseguraba la confidencialidad en el tratamiento de los datos.

En la tabla 1 se muestran las características de los progenitores entrevistados: nivel escolar, ocupación propia y del cónyuge, género y estado de la trayectoria escolar filial. La mayoría de las participantes fueron mujeres, algo esperable pues la implicación escolar es una labor fuertemente feminizada (Lareau, 200o). En el apartado de resultados se distingue entre progenitores de clase obrera (o clases populares) y de clase media, tal como proceden investigaciones similares (Rujas, 2016; Allen y White-Smith, 2018). En el primer grupo están incluidas familias cuyos progenitores poseen estudios básicos o medios y que trabajan como asalariados en ocupaciones rutinarias de baja cualificación. En el segundo grupo se encuentran las familias cuyos responsables poseen estudios superiores y trabajan en ocupaciones profesionales o tienen posiciones directivas.

Tabla 1

Entrevistados por origen social, sexo y rendimiento filial

\begin{tabular}{|c|c|c|c|c|}
\hline Nivel de estudios & Ocupación & $\begin{array}{l}\text { Ocupación } \\
\text { cónyuge }\end{array}$ & $\begin{array}{l}\text { Rendimiento filial } \\
\text { (primaria) y trayecto- } \\
\text { ria }(\mathrm{ESO})^{*}\end{array}$ & Sexo \\
\hline Superiores & \multicolumn{2}{|c|}{ Profesores de universidad } & Alto-Descendente & M \\
\hline Superiores & \multicolumn{2}{|c|}{ Pequeños empresarios } & Alto-Estable & M \\
\hline Superiores & Ingeniera & Abogado & Bajo-Ascendente & M \\
\hline Superiores & Prof. Secundaria & Ama de casa & Medio-Descendente & $\mathrm{H}$ \\
\hline Medios (BUP) & \multicolumn{2}{|c|}{ Pequeños empresarios } & Alto-Estable & $\mathrm{H}$ \\
\hline Superiores & Aux. de guardería & (Monoparental) & Medio-Descendente & M \\
\hline Superiores & Psicóloga & Periodista & Medio-Estable & M \\
\hline
\end{tabular}




\begin{tabular}{lllll} 
Primarios & Asist. doméstica & Fontanero & Alto-Estable & $\mathrm{M}$ \\
Incompletos & Ama de casa & Transportista & Medio-Ascendente & $\mathrm{M}$ \\
Incompletos & Asist. doméstica & Dependiente & Bajo-Estable & $\mathrm{M}$ \\
Primarios & Cocinera & Transportista & Alto-Estable & $\mathrm{M}$ \\
Medios (BUP) & Dependiente & Administrativa & Alto-Descendente & $\mathrm{H}$ \\
Medios (FP) & Cocinera & Comercial & Medio-Descendente & $\mathrm{M}$ \\
Superiores & Ama de casa & Ingeniero & Alto-Estable & $\mathrm{M}$ \\
Medios (FP) & Ama de casa & Mecánico & Alto-Estable & $\mathrm{M}$ \\
Medios (FP) & Ama de casa & Delineante & Bajo-Descendente & $\mathrm{M}$ \\
& & & Alto-Estable & \\
Primarios & Camarera & Jornalero & Medio-Descendente & $\mathrm{M}$ \\
Primarios & Encuadernadora & (Monoparental) & Bajo-Descendente & $\mathrm{M}$ \\
\hline
\end{tabular}

Fuente: elaboración propia.

${ }^{*}$ Se distingue entre rendimientos altos (suspensos inexistentes o muy ocasionales en primaria), medios (suspensos recurrentes, pero sin dificultades para promocionar) y bajos (suspensos habituales con dificultades para promocionar o habiendo repetido ya un curso). La trayectoria refiere al mantenimiento, mejoramiento o empeoramiento de las calificaciones filiales en 2.o de ESO respecto a las obtenidas en primaria.

** Ambos cónyuges estuvieron presentes en la primera entrevista. La segunda se realizó únicamente a la madre. La familia tiene hijos mellizos con trayectorias muy dispares.

Nos aproximamos a las percepciones docentes mediante el trabajo etnográfico. La etnografía es una herramienta especialmente adecuada para captar los discursos cotidianos y las formas más rutinarias de enjuiciamiento que circulan por la institución escolar (Franzé Mudanó, 2002). Para examinar las prácticas parentales se recurrió a entrevistas en profundidad. Partimos de que las relaciones entre familia y escuela son procesos sostenidos de interacción, a lo largo de los cuales las posturas de los actores van modificándose constreñidas por las acciones pasadas. Las entrevistas en profundidad son muy útiles para obtener información secuencial y facilitar la exposición de hechos cronológicamente ordenados, permitiendo al investigador reconstruir estas «cadenas de contingencias» (Becker, 2010: 54-55).

El análisis de los datos se fundamenta en un enfoque pragmático del discurso. Se parte de que los datos cualitativos son algo más que transmisiones de información o simples opiniones: son jugadas en las que se negocia la legitimidad de conductas y pensamientos (Martín Criado, 2014). Los sujetos no solo 
exponen sus comportamientos, también tratan de salvar la cara (Goffman, 1971) ante posibles juicios externos (los de la escuela, para las familias, y los de las familias, para el profesorado). Nos acercamos a las posiciones parentales y docentes - y a su interacción mutua - atendiendo a esta dimensión estratégica, analizando los discursos como prácticas que tratan de poner en valor los comportamientos propios.

Se comenzará exponiendo brevemente los discursos generales del profesorado acerca de la implicación familiar en los tres centros donde se realizó el trabajo de campo. Después, se compararán los discursos docentes sobre las familias analizadas con lo relatado por los propios progenitores en situación de entrevista. Tomaremos dos casos extremos de desajuste entre prácticas parentales declaradas y percepciones docentes de la mismas. No obstante, se mostrará que dicho desajuste existe (en diversos grados) para la mayoría de familias de la muestra. El rendimiento y comportamiento de los hijos e hijas es clave para entender este fenómeno, al condicionar simultáneamente los juicios docentes sobre la familia y la capacidad parental de mantener una implicación efectiva.

\section{FAMILIAS EN ABSTRACTO Y FAMILIAS EN CONCRETO}

Durante las reuniones de coordinación de tutores observadas, los problemas de rendimiento o el mal comportamiento de un sector del alumnado constituían un tema frecuente. Cuando estas cuestiones eran introducidas en la conversación, muchos profesionales aludían espontáneamente a las características familiares, sugiriendo un vínculo más o menos explícito entre la situación familiar del menor y su bajo desempeño escolar. En ocasiones muy concretas, se hacía referencia a las carencias materiales de los progenitores, sobre todo cuando dichas carencias son fácilmente deducibles a partir de los registros que se manejan en el centro (por ejemplo, cuando la familia está siendo atendida por los servicios sociales o cuando reside en zonas especialmente empobrecidas del espacio urbano). En otros casos, se apuntaba al tipo de relaciones intrafamiliares o a la propia estructura del hogar, bajo el concepto-paraguas de familia desestructurada: padres «muy jóvenes», hijos a cargo de tíos o abuelos, relaciones conflictivas con los hijos o entre los cónyuges, hermanos mayores que ejercen una influencia perniciosa, etc.

La mayoría de las veces, no obstante, los déficits imputados a las familias eran de voluntad parental: indulgencia con los hijos o las hijas, despreocupa- 
ción por la escuela o una combinación de ambas. La ausencia de implicación rara vez se enunciaba de forma explícita, sino que se presuponía evidente como producto del desinterés familiar por lo escolar. De hecho, es difícil distinguir la falta de preocupación de la falta de implicación en los juicios docentes sobre las familias. Ambos déficits tienden a quedar solapados en expresiones relativamente ambiguas o coloquiales: se habla de padres que «no controlan», que «consienten todo», que «no están pendientes» o que «pasan del tema». Además, era habitual que los profesores vinculasen la falta de control sobre la trayectoria escolar con un descontrol sobre la vida filial en sentido más amplio:

Se habla de varios alumnos de primero de ESO cuyo comportamiento es definido como conflictivo (acumulan muchos partes de conducta). Como en reuniones anteriores, cuando sus nombres son mencionados, los tutores reaccionan hablando sobre sus familias. En la mayoría de los casos, se ha intentado contactar con los progenitores, sin éxito. Solo en un caso pudo hablarse con la madre por teléfono. Habla su tutora: «no controla nada, no tiene ni idea de nada de cómo va su hijo, ni sabe nada de lo que hace fuera de casa». Habla la jefa de estudios: «sin el apoyo familiar no podemos hacer nada». (Cuaderno de campo, reunión de coordinación de tutores, 1. ํㅡㄹ de ESO, IES Alcázar.)

La literatura sobre la relación familia-escuela ha señalado que las percepciones docentes sobre las familias están muy ligadas al origen social del alumnado. En los institutos donde se realizó el trabajo de campo, el estatus social del público ejercía una visible influencia en las consideraciones más globales o generalistas del profesorado. Esto es, en los momentos en que el discurso docente se refiere a las familias como los habitantes del entorno del centro (entorno que puede ser más o menos difícil). En ese sentido, en el IES Jorge Manrique se hablaba de las familias en tonos positivos, dando por sentado una gran implicación. Mientras, en los IES Alcázar y García Lorca eran habituales las descalificaciones colectivas de los progenitores. Sin embargo, estas valoraciones grupales conviven con juicios diferenciados a la hora de hablar de familias concretas. En estos casos, las inferencias docentes de las prácticas parentales se centran mucho más en a) la asistencia o evitación de las reuniones de tutoría y $b$ ) el rendimiento y la conducta del hijo en el centro.

En los tres establecimientos, el hecho de acudir al centro cuando se es convocado se interpretaba como una señal mínima de adhesión familiar al proyecto escolar. Dichas consideraciones eran abiertamente transmitidas a las familias (en especial en los centros de composición social inferior: Alcázar y García Lorca). Por ejemplo, durante la reunión inicial con las familias en el IES 
Alcázar, el equipo directivo instó a los asistentes a firmar una hoja de asistencia argumentando que era «muy importante saber quién ha venido, pero, sobre todo, quién no ha venido».

Esta implicación visible se valora como un mínimo necesario, pero no suficiente. Los progenitores que evitan las reuniones o las tutorías son automáticamente catalogados como faltos de interés, pero la simple asistencia al centro no garantizaba una imagen positiva de la familia en las percepciones docentes. Excepto un caso, todos los progenitores entrevistados durante la investigación acudían a los centros cuando eran convocados y muchos acudían por iniciativa propia (normalmente, después de evaluaciones desfavorables). A pesar de ello, algunas de las familias participantes en la investigación eran juzgadas negativamente en los establecimientos.

Cuando el investigador preguntaba a los tutores específicamente por los progenitores entrevistados, la pauta era muy clara: si el desempeño escolar del hijo era óptimo, sus familias eran evaluadas invariablemente de forma positiva, descritas como padres que se preocupan y «están encima». En caso contrario, solía acusarse a la familia de no «poner de su parte» y de no apoyar la labor de la escuela, sobre todo cuando las bajas calificaciones coexisten con problemas disciplinarios. Estos juicios comenzaban a ponerse en juego incluso en las

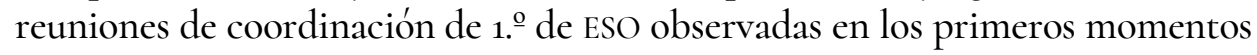
del curso escolar, antes de que los tutores hubieran establecido contactos personalizados con la mayoría de las familias.

Conversación con varios profesores tras una reunión de coordinación de tutores. Se ha hablado de varios alumnos con problemas disciplinarios reiterados. Uno de ellos es R., cuya madre ha sido entrevistada en la investigación. Su tutor ha comentado que su familia «no parece que esté muy pendiente». Le vuelvo a sacar el tema informalmente y, como si respondiera a una pregunta muy evidente, me responde «eso se nota». Otra profesora interviene: «eso es algo que, cuando sabes cómo va la cosa, se ve». (Cuaderno de campo, reunión de coordinación de tutores, $1 .^{\circ}$ de ESO, IES Alcázar.)

Así, muchas percepciones docentes sobre la implicación de las familias preexisten a los encuentros efectivos con ellas, pues se construyen esencialmente sobre el comportamiento y el rendimiento de los hijos e hijas. Dichas percepciones no coincidían con los relatos de los progenitores obtenidos en situación de entrevista. Como se mostrará en los siguientes apartados, familias catalogadas como «no colaboradoras» declaraban importantes estrategias de supervisión escolar (y viceversa, progenitores considerados «implicados» en los centros exponían débiles prácticas de control). Sin embargo, la pauta más co- 
mún es que los posteriores encuentros con los progenitores no modifiquen las percepciones docentes, sino que las reafirmen. El análisis de las reuniones de tutoría y su puesta en común con las entrevistas nos ofrece una gran oportunidad para comprender este fenómeno. El discurrir de las reuniones entre progenitores y docentes solo puede entenderse teniendo en cuenta lo que sucede en los hogares.

\section{UNA IMPLICACIÓN SOBREESTIMADA}

Ana (nombre ficticio) es una madre de clase obrera cuya hija cursa el primer ciclo de la ESO en el IES Alcázar. Su hija ha sido delegada de clase y el profesorado la considera una alumna modelo debido a su buen comportamiento y sus altas calificaciones. Tales consideraciones positivas se hacían extensivas a su familia. Cuando el investigador preguntaba por sus progenitores, se hablaba de ellos como padres «que están encima», comentando que «ya podrían ser todos así». Durante las entrevistas, Ana confiesa abiertamente que su intervención en la rutina escolar de su hija es mínima. La propia menor gestiona sus tiempos y prepara sus tareas y exámenes sin ningún tipo de supervisión ni regulación parental. Su madre expone la situación con orgullo: su hija es responsable y merece su total confianza.

Sin embargo, Ana está perfectamente al tanto de los entresijos de la vida académica de su hija. No necesita solicitarle información activamente, la menor la comparte motu proprio. Hablar del día a día en la escuela (de los profesores, las calificaciones, los contenidos y las tareas) va consolidándose como una rutina doméstica. Dados sus buenos resultados, su hija no tiene problema en comentar con sus padres la marcha cotidiana del curso. Todo lo contrario, pues cuenta con el incentivo de ganar un reconocimiento simbólico en el hogar. Además, es habitual que la hija trate de usar sus éxitos escolares de cara a negociar cesiones de derechos con los progenitores: por ejemplo, solicita acceso a ciertas formas de consumo o a tiempo de ocio no vigilado a cambio de sus buenas calificaciones. Todas estas situaciones se repiten en familias con hijos e hijas escolarmente exitosos, en todas las clases sociales. En estos casos, los progenitores están muy bien informados de lo que sucede en la escuela, a pesar de intervenir poco o nada en las tareas escolares cotidianas. La idea de implicación va abandonándose en favor de una paulatina responsabilización de los hijos e hijas, que hasta ahora ha dado buenos resultados. En este proceso, llegan a cuestionarse algunos de los dictámenes del profesorado: 
Yo siempre digo, siempre, que sus tareas son sus tareas y tienen esa responsabilidad. Ellas tienen que saber lo que tienen que hacer, yo no les voy a mirar si tienen la agenda o... Además, que eso se lo dije yo una vez a la señorita. Me dice «es que a los niños hay que mirarles la agenda». Y le digo «iPerdona?». No, eso es responsabilidad suya y yo no tengo por qué mirarles la agenda, porque ese es su trabajo y son ellas las que saben que lo tienen que hacer. Yo confío en ellas. (Mujer, clase obrera, trayectoria filial altaestable, 1. ${ }^{\mathrm{a}}$ entrevista.)

La falta de control sobre la rutina escolar filial $-\mathrm{y}$ su distancia crítica hacia los juicios docentes - contrasta con los discursos del profesorado alrededor de estas familias. Por el alto rendimiento y la conducta obediente de los hijos e hijas, el cuerpo docente presupone unos padres implicados en la escolaridad. Dicha suposición se ve reforzada durante las reuniones de tutoría. Existe un patrón que se repite durante estos encuentros: el tutor siempre trata de tantear en qué medida los progenitores están al corriente del estado de la trayectoria filial (de las calificaciones recientes, de las amonestaciones, de las obligaciones asignadas, etc.). El docente no puede acceder directamente a lo que sucede en el hogar ni conocer las prácticas concretas de vigilancia puestas en marcha por la familia. Al ser cuestionados, los progenitores siempre podrían exagerar sus esfuerzos de cara a defender su imagen y demostrar una actitud proescolar. Para el tutor, la información que los progenitores muestran poseer constituye el baremo más fiable de su implicación:

Conversación con la tutora de $1 .^{\circ}$ A después de una reunión de tutoría. Me he fijado en que empieza las reuniones preguntando a los padres qué notas o cuántos suspensos se esperan (quedan pocos días para que se entreguen las notas de la segunda evaluación). Le pregunto el porqué de esa costumbre y ella responde, como si fuera un importante saber del oficio, que «es la mejor manera de saber si están encima o no». (Cuaderno de campo, IES Jorge Manrique, conversación postutoría de $1 .^{\mathrm{o}} \mathrm{A}$.)

En las familias con hijos e hijas escolarmente exitosos, los progenitores manejan abundante información sobre la vida escolar del menor (quien la comparte sin problemas en el hogar al no perjudicarle) y conocen de antemano la mayoría de las opiniones docentes (que, además, son positivas). Aún más: los niños con mejores rendimientos suelen mantener relaciones cordiales con sus profesores y difundir imágenes benévolas de ellos en el hogar. Los progenitores acuden positivamente predispuestos a sus reuniones con el tutor, en sintonía con la preocupación y el interés que el tutor intuye en ellos. Y los encuentros, al discurrir apaciblemente y sin protestas por ninguna de las partes, terminan por confirmar las creencias previas de unos y otros. 
Esta dinámica explica una paradoja, que muestra la comparación entre las entrevistas y la observación etnográfica en los establecimientos: las familias consideradas en los centros como más implicadas eran, en muchos casos, las que menos tiempos y energías dedicaban a monitorizar la trayectoria filial (aunque todas ellas conferían gran importancia a la escuela y mostraban altas expectativas sobre el futuro escolar de los hijos e hijas). En algunos casos, la falta de concordancia entre percepciones docentes y estrategias parentales puede quedar al descubierto. Así sucedió en una reunión de tutoría del IES Jorge Manrique. Se trataba de una pareja de clase media cuya hija es una estudiante excelente. Mientras la tutora se deshacía en halagos hacia los padres, ellos recalcaban en varias ocasiones que su papel en la escolaridad filial era muy discreto:

Profesora: Pero... excepcional, en todos los aspectos, que eso también implica un equilibrio... muy buena compañera, muy solidaria, con muchos valores muy positivos... y yo por eso quería llamarles para darles la enhorabuena, que no todo va a ser...

Madre: Yo ya te digo que es que es desde que nació, responsable... tranquila, no se altera con nada... Estamos muy contentos.

Padre - Es que ella es así. Es que ella, desde chiquitita, no hemos tenido que hacer mucho, casi nada. Ella se ha puesto, se organiza, sus cosas, todo... Y, claro, con las buenas notas que saca, no le podemos decir nada...

Profesora: Hombre, así no nació seguro, que «es desde que nació»... Los niños no nacen así. No nacen así. Algo de culpa tendrán ustedes. [Ríe.] Es una evolución, o sea que le va a ir todo muy bien. (Reunión de tutoría, pareja de clase media, trayectoria filial altaestable.)

Todo ello no quiere decir que el profesorado sea totalmente ajeno a la progresiva independencia de los hijos e hijas para organizar su trabajo escolar (más cuando los propios docentes tienen vástagos en edad escolar que estudian de forma autónoma). De ahí el significado ambiguo que el discurso docente atribuye frecuentemente a la categoría apoyo parental. La familia sería responsable de los éxitos y los fracasos escolares, pero no solo por su grado de intervención directa en lo escolar, sino por un conjunto de características actitudinales más difusas: interés, preocupación, disciplina, mantenimiento de un orden afectivo, etc. 


\section{UN ESFUERZO INVISIBLE}

Isabel (nombre ficticio) es una madre de clase obrera cuyo hijo mayor está matriculado en el IES Alcázar. Tras algunos problemas en primaria, su hijo comienza a suspender la mayoría de asignaturas tras su acceso a la ESO. Su comportamiento en el aula se ha vuelto desobediente y tiene constantes enfrentamientos con los docentes. Durante las reuniones de coordinación y en conversaciones con sus profesores, estos acusan a la familia de despreocupación y falta de control sobre su rutina escolar. Durante las entrevistas, Isabel relata con angustia cómo intenta dirigir a su hijo hacia el trabajo escolar, regulando sus horarios de estudio y revisando esporádicamente sus tareas. También acude al centro a hablar con los profesores y castiga a su hijo cuando llegan las malas calificaciones (limitando el acceso a ciertos bienes de consumo o a tiempo de ocio). Pero esta inversión no da sus frutos.

Al igual que sucede en otras familias donde los niños obtienen bajas calificaciones, el hijo de Isabel ha desarrollado una actitud hostil hacia el trabajo escolar. Una queja se repite en las entrevistas con este tipo de familias: los hijos e hijas cuentan muy poco de lo que les pasa en la escuela. Cuando los progenitores preguntan, solo obtienen evasivas, respuestas superficiales o anécdotas sin relación con los aprendizajes. Por otro lado, estos niños suelen oponerse al control sobre sus tareas, reaccionando con negativas explícitas a las medidas que los progenitores pretenden tomar en el hogar. Las insistencias parentales pueden desembocar en todo tipo de conflictos: reproches, discusiones, amenazas de castigos tremendos, etc. Esta dinámica refuerza la poca disposición de los hijos e hijas a colaborar y su interés en mantener a los padres desinformados. De ahí que, además de enfrentarse directamente a los progenitores, los hijos e hijas pongan en marcha tretas para burlar la vigilancia parental. Los progenitores relatan cómo intentan ocultarles información o, directamente, engañarles (con las calificaciones, las fechas de los exámenes, las tareas asignadas):

Él me cuenta cuando aprueba. Cuando no aprueba, lo veo cuando tengo que firmarlo. Él no me lo cuenta. Mentir, miente muy poco, ¿vale? Pero con las cosas del instituto un poquito más. Y él, cuando ha suspendido, le miente a la maestra, le miente... «Pues la agenda me la he dejado en casa de mis abuelos». Y ahora a mí: «Pues la agenda me la he dejado en clase». Que yo me quedo... «Nene ¿por qué me mientes?». (Mujer, clase obre-

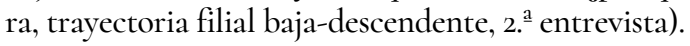


Cuando a la resistencia filial se suma un bajo capital cultural, es muy probable que los boicots de los hijos e hijas tengan éxito y los progenitores acaben manejando versiones distorsionadas de la situación escolar del menor (faltos de competencias escolares, han de confiar más en los relatos interesados de los hijos). En estas circunstancias, para los progenitores es muy difícil certificar con exactitud el cumplimiento de las tareas u obtener información veraz sobre las calificaciones o las posibles amonestaciones. ${ }^{3}$ Pese a las constantes preguntas, las riñas, las medidas de control y los castigos, los hijos e hijas tienen amplias posibilidades para mantener a sus progenitores convenientemente desinformados:

Lo castigo, lo tengo en su cuarto... Además, él te protesta. Vamos que, evidentemente, él es mucho más alto que yo, y... «A tu habitación.» «Pero, ¿por qué?» Vamos a ver, yo te voy a dar una explicación hasta cierto punto, tú no sales de tu habitación porque he recibido una carta, tú no haces los deberes [...] Y... ahora, por ejemplo, llegaré a casa [la entrevista fue en su lugar de trabajo], le preguntaré: «iHas hecho los deberes?» «Sí.» «Enséñame qué es lo que has hecho...» Ya, y me enseña un papel y tú lo has escrito hace media hora, yo no sé si lo has escrito hace media hora o hace tres días. Porque ya no tengo una referencia... (Mujer, clase obrera, trayectoria filial media-descendente, $2 .{ }^{a}$ entrevista).

Esta configuración de relaciones alrededor del trabajo escolar doméstico tiene efectos importantísimos en la relación familiar con el cuerpo docente. En estas familias —donde coinciden malos resultados y bajo capital cultural- los encuentros con los tutores de los hijos e hijas suelen ser muy tensos. Primero, porque el docente presupone que tras los problemas escolares del alumno hay una familia que no se preocupa. Segundo, porque durante la reunión los progenitores evidencian estar poco o mal informados de lo que sucede (dadas las resistencias, distorsiones y ocultaciones de los hijos e hijas). Dicha ignorancia es rápidamente captada por el tutor, lo que confirma sus sospechas previas de que la familia no demuestra interés por la escuela ni disciplina adecuadamente a su hijo. Un caso muy claro pudo observarse durante una de las reuniones de tutoría a la que acudió Isabel en el IES Alcázar. Ella y su cónyuge acuden al centro desconociendo que su hijo acumula

3 Una de las grandes evidencias que nos proporciona el análisis longitudinal es que esta situación se agrava con el tiempo si la actitud y el rendimiento escolar del menor no mejoran. Por un lado, los hijos van afinando sus estrategias elusivas; por otro, los progenitores entienden cada vez menos los contenidos que han de trabajar. 
numerosos suspensos y partes de conducta, ya que este había devuelto todas las notificaciones falsificando la firma de su madre.

Profesora: Pero cuando yo he visto la agenda, ahí había por lo menos tres o cuatro notas de otras asignaturas que habían aparecido firmadas.

Madre: Pero si él no ha traído ninguno... pero... notas en la agenda, pero no de exámenes, ¿no?

Profesora: [Endurece el tono] No, no. Sí, notas de exámenes. [Madre, trata de interrumpir: «Pero, el examen...»]. No, yo no entrego el examen. Pero, vamos, lo lleva corregido. Lleva su nota del examen, y el examen corregido y eso ha aparecido firmado. [Endurece el tono aún más.] Y, luego, si ustedes quieren verlo, yo les enseño el examen. (Reunión de tutoría, pareja de clase obrera, trayectoria filial media-descendente.)

Los docentes pueden advertir que el desconocimiento parental es producto de las maniobras de los hijos o hijas, pero ello no acaba de exculpar a la familia. De hecho, la profesora que protagoniza el anterior verbatim acusaba a los padres - en posteriores conversaciones con el investigador- de «no ponerse firmes»y de «dejarse engañar». Las resistencias del hijo al control parental son entendidas como producto de una mala socialización a la que los progenitores tampoco querrían poner remedio.

A esta percepción contribuye una maniobra habitual de estos progenitores durante las tutorías. Ante las malas noticias y las inculpaciones docentes, tratan de poner en valor las virtudes morales de los hijos e hijas. Inciden en que, al margen de su vida académica, se trataría de niños buenos, cariñosos o respetuosos. Dada su escasa información sobre los aprendizajes (y dadas las bajas calificaciones de sus vástagos), la mejor forma de valorizar al menor frente al tutor es salirse del ámbito escolar. Estas jugadas, concebidas como defensa de la imagen de sí, suelen tener efectos contrarios a los perseguidos: refuerzan la creencia del tutor de que los padres eluden sus responsabilidades y prefieren no enfrentarse a la situación. El cuerpo docente está acostumbrado a lidiar con la faceta escolar del alumno (definida como disruptiva) y recibe con incredulidad los intentos parentales de dignificación. Esto explica un lamento recurrente en las reuniones de coordinación de tutores: las familias de los malos estudiantes siempre tratarían de exculparles, anteponiendo un cariño mal entendido a su compromiso con lo escolar: 
Los docentes hablan de un grupo-clase donde abundan los comportamientos antiescolares. Se ha hablado con las familias de los alumnos considerados más conflictivos. Una profesora comenta: «Quieren que lo hagamos todo nosotros, pero ellos mismos les consienten ese comportamiento en casa». Otra profesora se dirige a mí: «Es que aquí, para los padres, los hijos siempre son [imita el acento] 'mu güeno' y 'nunca hacen na' ¿sabes?». (Cuaderno de campo, reunión de coordinación de tutores, $1 .{ }^{\circ}$ de ESO, IES García Lorca.)

Los problemas académicos del menor, el relativo desconocimiento parental de la situación y los fallidos intentos de salvar la cara frente a los tutores explican que estas familias sean etiquetadas como no implicadas, aun cuando continúan acudiendo al centro (y aun cuando ponen en marcha estrategias, poco exitosas, de control escolar en el hogar), si bien los alegatos docentes sobre la mala conducta filial son vividos con visible incomodidad por los progenitores. Si el comportamiento no mejora, la continua degradación simbólica que suponen estos encuentros -y la percepción de que no son útiles para revertir la situación- puede desanimar a la familia, que progresivamente acude menos al centro.

Porque siempre, de que... «Se porta mal en plástica». Él odia la plástica, la asignatura, y la profesora me lo dice tal cual: «Él odia mi asignatura». Le faltó decirlo con... Vamos a ver, señora, si él odia su asignatura... Como si el niño fuera tonto. «Mira, es que hasta la regla la coge mal, no tiene destreza...» Como digo yo, no tiene gran habilidad en los dedos, sí, tiene esa dificultad un poco [...] Digo «Mira, cirujano no va a ser, no tendrá esa habilidad» o no podrá ser muchas cosas. Digo «Mira, que sea albañil, pero que sea feliz que es lo importante» ¿Sabes? [Sube el tono, indignada.] Es que siempre me cuentan cosas negativas. Y ahora está con el «Voy a suspender, voy a suspender». A ver si me dicen que va a repetir el curso. Es que cada vez que voy se me quitan las ganas de volver. (Mujer, clase obrera, trayectoria filial mediadescendente, $2 .^{\circ}$ entrevista.)

Durante la segunda fase de entrevistas, las familias de clases populares cuyos hijos o hijas experimentaban problemas afirmaban haber reducido su frecuencia de contacto con los tutores (aunque solo una madre de la muestra evitaba totalmente las reuniones). ${ }^{4}$ En los centros, este cambio de acti-

4 Esta madre pertenecía a una fracción precaria de la clase obrera (estudios primarios incompletos, acceso intermitente al empleo) y su hijo mostraba, ya desde primaria, graves problemas de aprendizaje y una oposición frontal al control parental. Esta madre contactó en muchas ocasiones con el profesorado durante la etapa primaria, pero con el paso a la ESO dejó de hacerlo. En este caso, el historial de tensiones que lleva a un descenso de los contactos comenzó en un momento temprano de la carrera escolar filial. 
tud termina por apuntalar la percepción docente de que la familia ni se interesa ni se implica.

\section{CONCLUSIONES}

A tenor de las investigaciones existentes, un importante sector del profesorado considera que las familias de su alumnado no se implican lo suficiente en su educación formal. Pero la información directa que los docentes tienen sobre las familias y sus prácticas es muy limitada. Por tanto, resulta de interés entender cómo se conforman los juicios docentes sobre las familias y en qué medida coincide con lo que ocurre en los hogares. Nuestros resultados muestran que las inferencias del profesorado sobre la implicación de las familias no concuerdan, en muchos casos, con lo relatado por las propias familias. Varias dinámicas contribuyen a explicar este desajuste.

Primero, el profesorado supone que la implicación es más débil en aquellas familias cuyos hijos o hijas tienen problemas de rendimiento y mal comportamiento. Las entrevistas muestran que, precisamente en esos hogares, las medidas de control del trabajo escolar son más intensas (aunque no siempre tengan los efectos deseados). En cambio, el seguimiento continuo de la escolaridad es muy poco frecuente en familias donde los hijos e hijas consolidan una trayectoria exitosa, que suelen ser consideradas «familias implicadas» en los discursos docentes.

Segundo, el cuerpo docente percibe que aquellas familias peor informadas de la trayectoria filial suelen tener hijos o hijas con problemas académicos y conductuales. Esto es habitualmente interpretado como desinterés y como explicación al bajo rendimiento del alumno. Sin embargo, la información que los progenitores pueden obtener no depende únicamente de su interés o de sus prácticas de control, y menos aún conforme los y las menores crecen. También depende de las voluntades y estrategias de los hijos e hijas, muy ligadas a sus calificaciones y su gusto por la escuela. Algunas familias, especialmente aquellas con un bajo capital cultural, pueden desplegar enormes esfuerzos para fiscalizar el trabajo de los hijos o hijas sin tener ningún éxito.

Tercero, el profesorado advierte que muchas familias con hijos e hijas más antiescolares evitan directamente el contacto con la institución. Desde el punto de vista docente, este comportamiento demostraría falta de implicación, que a su vez provocaría las dificultades académicas del menor. El discurso de las familias es muy distinto: se acude cada vez menos porque el mal compor- 
tamiento del hijo o hija lleva a desencuentros con los docentes y las reuniones con los tutores se convierten en malas experiencias a las que no se ve ningún provecho.

Estas dinámicas explican un hallazgo recurrente de la literatura: en los estudios transversales, el rendimiento del alumnado correlaciona más con la implicación parental percibida por el profesorado que con la declarada por las familias (Reynolds, 1992; Bakker, Denessen y Brus-Laeven, 2007; Hill y Tyson, 2009). Los resultados del presente estudio nos llevan a ser cautelosos a la hora de utilizar las percepciones del profesorado para medir la implicación parental. Esta advertencia es especialmente relevante cuando se pretende averiguar el peso explicativo de la implicación parental sobre el rendimiento del alumnado: la implicación percibida podría interpretarse como causa cuando en buena medida es un efecto.

Asimismo, la relación entre estatus social e implicación parental puede aparecer distorsionada cuando esta última se mide a partir de las percepciones docentes (Bakker, Denessen y Brus-Laeven, 2007). El hecho de que el profesorado perciba menor implicación en estratos inferiores se ha vinculado a prejuicios (Allen y White-Smith, 2018) o a las competencias culturales y lingüísticas que los progenitores demuestran en las reuniones con los docentes (Weininger y Lareau, 2003). Esta investigación obliga a prestar atención a las medidas de control que las familias despliegan en el hogar y a la eficacia de las mismas. Ante malos resultados filiales, un bajo capital cultural supone enormes problemas para practicar una implicación efectiva. Incapaces de revertir la situación y crecientemente desinformadas sobre la trayectoria del menor, las familias de clase obrera lo tienen mucho más difícil para poner en valor su implicación parental frente al cuerpo docente.

En cuanto a las limitaciones del estudio, hemos de señalar la escasa participación de padres varones en las entrevistas, lo que resulta un obstáculo para el análisis de la división de género en la implicación parental. También sería interesante incluir más casos de familias no tradicionales (monoparentales, homoparentales), pues ya hay investigaciones que detectan patrones diferenciados en su relación con la escuela (Rosenfeld, 2010).

\section{BIBLIOGRAFÍA}

Allen, Quaylan y White-Smith, Kimberly (2018). That's why I say 'stay in school': Black mothers' parental involvement, cultural wealth and 
exclusion in their son's schooling. Urban Education, 53(3), 409-435. doi: $10.1177 / 0042085917714516$

Alonso Carmona, Carlos (2014). Familia, escuela y clase social. Sobre los efectos perversos de la implicación familiar. Revista de la Asociación de Sociología de la Educación, 7(2), 395-409.

Bakker, Joep, Denessen, Eddie y Brus-Laeven, Mariël (2007). Socioeconomic background, parental involvement and teacher perceptions of these in relation to pupil achievement. Educational Studies, 33(3), 177-192. doi: 10.1080/03055690601068345

Becker, Howard (2010). Trucos del oficio. Cómo conducir su investigación en ciencias sociales. Madrid: Siglo XXI.

Bourdieu, Pierre (1987). Los tres estados del capital cultural. Sociológica, $2(5), 11-17$.

Cabrera, Blas, Cabrera, Leopoldo, Pérez Sánchez, Carmen N. y Zamora, Begoña (2011). La desigualdad legítima de la escuela justa. Revista de la Asociación de Sociología de la Educación, 41(1), 307-335.

Castejón, Alba (2017). Expectativas docentes, agrupamiento del alumnado y segregación escolar: una etnografía en entornos de alta complejidad social en Cataluña. Tesis doctoral. Barcelona: Universitat Autònoma de Barcelona.

Cerletti, Laura y Santillán, Laura (2018). Responsabilidades adultas en la educación y el cuidado infantil. Discusiones histórico-etnográficas. Cuadernos de Antropología Social, 47, 87-103. doi: 10.34096/cas.i 47.3842

Franzé Mudanó, Adela (2002). Lo que sabía no valía. Madrid: CES de Madrid.

Garreta Bochaca, Jordi (2017). Familias y escuelas. Discursos y prácticas sobre la participación en la escuela. Madrid: Pirámide.

Goffman, Erving (1971). La presentación de la persona en la vida cotidiana. Buenos Aires: Amorrortu.

Gomáriz Vicente, María Ángeles, Hernández-Prados, María Ángeles, García-Sanz, María Paz y Parra-Martínez, Joaquín (2016). Tejiendo puentes entre la escuela y la familia. El papel del profesorado. Bordón, 69(2), 41-57.

Hill, Nancy E. y Tyson, Diana F. (2009). Parental involvement in middle school: a meta-analytic assessment of the strategies that promote achievement. Developmental Psychology, 45(3), 740-763. doi: 10.1037/a0015362 
Iruka, Iheoma U., Winn, Donna-Marie C., Kingsley, Susan J. y Orthodoxou, Yannick J. (2011). Links between parent-teacher relationships and kindergartners' social skills: Do child ethnicity and family income matter? The Elementary School Journal, 111(3), $387-408$.

Lareau, Annette (2000). Home Advantage. Social class and parental intervention in Elementary education. Lanham: Rowman \& Littlefield Publishers.

Lawson, Michael (2003). School-family relations in context. Parent and teacher perceptions of parent involvement. Urban Education, 38(1), 77-133. doi: 10.1177/0042085902238687

López Larrosa, Silvia, Richards, Andrew, Morao Rodríguez, Silvia y Gómez Soriano, Laura (2019). Teachers and trainee teachers' beliefs about family-school relationships. Aula Abierta, 48(1), 59-66.

Madrid, Romina, Saracostti, Mahia, Reininger, Taly y Hernández, María Teresa (2019). Responsabilización, obediencia y resistencia: perspectivas de docentes y padres sobre la colaboración familia-escuela. Revista Electrónica Interuniversitaria de Formación del Profesorado, $22(3), 1-13$.

Martín Criado, Enrique (2014). Mentiras, inconsistencias y ambivalencias. Teoría de la acción y análisis de discurso. Revista Internacional de Sociología, 72(1), 115-138.

Martín Criado, Enrique, Carvajal Soria, Pilar y Río Ruíz, Manuel Ángel (2014). Prácticas de socialización y relaciones con la escolaridad de las familias más alejadas de la norma escolar. Revista de la Asociación de Sociología de la Educación, 7(2), 429-448.

Martín Gimeno, Rubén y Bruquetas Callejo, Carlos (2014). La evolución de la importancia del capital escolar en la clase obrera. Revista de la Asociación de Sociología de la Educación, 7(2), 373-394.

Minke, Kathleen M., Sheridan, Susan, Kim, Elizabeth M., Ryoo, Ji Hoon y Koziol, Natalie A. (2014). Congruence in parent-teacher relationships: The role of shared perceptions. The Elementary School Journal, 114(4), 527-546. doi: 10.1086/675637

Morales Romo, Noelia (2006). Padres y profesores, dos importantes agentes sociales en las organizaciones escolares españolas y sus interrelaciones en un contexto glocal. Convergencia, 13(41), 87-116.

Pérez Díaz, Víctor, Rodríguez, Juan Carlos y Fernández, Juan Jesús (2009). Educación y familia. Papeles de Economía Española, 119, 36-58. 
Pérez Sánchez, Carmen N. y Noda Rodríguez, María del Mar (2012). La familia en el punto de mira del profesorado. En Bonal, Xavier, Díaz, Capitolina y Luque, David (Eds.). Actas de la XVI Conferencia de Sociología de la Educación (743-756). Oviedo: Asociación de Sociología de la Educación.

Perrenoud, Philippe (1987). Le Go-Between: Entre sa famille et l'école, l'enfant messager et message. En Montandon, Cleopatre y Perrenoud, Philippe (Eds.). Entre Parents et Enseignants: Un Dialogue Impossible? (49-87). Berna: Peter Lang.

Reynolds, Arthur (1992). Comparing measures of parental involvement and their effects on academic achievement. Early Childhood Research Quarterly, 73(3), 441-462. doi: 10.1016/0885-2006(92)90031-s

Río Ruiz, Manuel Ángel (2010). No quieren, no saben, no pueden. Categorizaciones sobre las familias más alejadas de la norma escolar. Revista Española de Sociología, 14, 85-105.

Robinson, Keith y Harris, Angel (2014). The Broken Compass. Parental involvement with Children's Education. Cambridge: The Harvard University Press.

Rosenfeld, Michael J. (2010). Nontraditional families and childhood progress through school. Demography, 47(3), 755-775.

Rujas, Javier (2016). Como juzga la escuela a las familias. Revista de la Asociación de Sociología de la Educación, 93(3), 385-396.

Tarabini, Aina (2015). La meritocracia en la mente del profesorado. Un análisis de los discursos docentes en relación al éxito, fracaso y abandono escolar. Revista de la Asociación de Sociología de la Educación, 8(3), 349-360.

Weininger, Elliot B. y Lareau, Annette (2003). Translating Bourdieu into American context: The question of social class and familyschool relationships. Poetics, 31(5-6), 375-402. doi: 10.1016/so3o4422x(03)ooo34-2

Wong, Shuk W. y Hughes, Jan N. (2006). Ethnicity and language contributions to dimensions of parent involvement. School Psychology Review, 35(4), 645-662. doi: 10.1080/o2796015.2006.12087968 